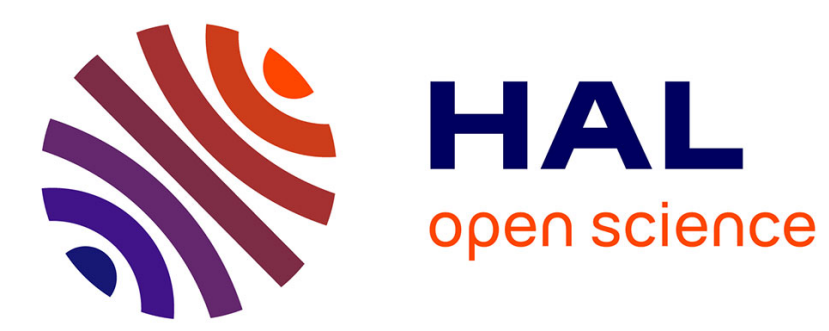

\title{
Tunable luminescence from Ce-doped aluminoborosilicate glasses
}

\author{
E Malchukova, B Boizot
}

\section{To cite this version:}

E Malchukova, B Boizot. Tunable luminescence from Ce-doped aluminoborosilicate glasses. Journal of Rare Earths, 2014, 32, pp.217-220. 10.1016/S1002-0721(14)60055-7 . cea-01120988

\section{HAL Id: cea-01120988 https://hal-cea.archives-ouvertes.fr/cea-01120988}

Submitted on 27 Feb 2015

HAL is a multi-disciplinary open access archive for the deposit and dissemination of scientific research documents, whether they are published or not. The documents may come from teaching and research institutions in France or abroad, or from public or private research centers.
L'archive ouverte pluridisciplinaire HAL, est destinée au dépôt et à la diffusion de documents scientifiques de niveau recherche, publiés ou non, émanant des établissements d'enseignement et de recherche français ou étrangers, des laboratoires publics ou privés. 


\title{
Tunable luminescence from Ce-doped aluminoborosilicate glasses
}

\author{
E. Malchukova ${ }^{1,2, *}$, B. Boizot ${ }^{2}$ \\ (1. Ioffe Physical Technical Institute, Polytechnicheskaya St., 26, Saint-Petersburg, 194021, Russia; 2. CEA, IRAMIS, Laboratoire des Solides Irradiés, Ecole \\ Polytechnique, CNRS, 91128 Palaiseau, France)
}

Received 11 June 2013; revised 8 November 2013

\begin{abstract}
A series of aluminoborosilicate glasses were prepared using the melt-quenching technique for mixture of stoichiometric amounts of $\mathrm{SiO}_{2}, \mathrm{Al}_{2} \mathrm{O}_{3}, \mathrm{H}_{3} \mathrm{BO}_{3}, \mathrm{Na}_{2} \mathrm{CO}_{3}$, and $\mathrm{ZrO}_{2}$ with adding of different amounts of $\mathrm{CeO}_{2}$. The samples were investigated by means of luminescence spectroscopy. Tunable luminescence from violet to blue/green was observed from these glasses with different Xe-lamp excitation wavelengths ranging from 370 to $480 \mathrm{~nm}$ as well as with laser excitation of 266 and $355 \mathrm{~nm}$. Moreover it was found that the possibility of tuning the light by changing of excitation wavelength was not unique. The same effect was observed by adjusting conditions for luminescence measurements as well as under exposure to $\beta$-irradiation. The obtained phenomena could be explained taking into account structural characteristics of this glass and it could be concluded that tunable luminescence results from the presence of different Ce-sites the glass matrix. Thus the results suggest that Ce-doped glasses could be considered as conversion materials for blue light-emitting diode chips to generate white light-emitting diodes.
\end{abstract}

Keywords: Ce-doped glass; tunable emission; different RE sites; rare earths

$\mathrm{Ce}^{3+}$ ions were widely used as activators in various fluoride and oxide materials. The preparation of REdoped phosphor materials for application in advanced illumination technologies has been the subject of intense research during recent decades. These researches are stimulated by the necessity of increasing the efficiency in white light emitting solid state devices which represent an alternate lightning source ${ }^{[1]}$. Despite existing of well-known and exploited crystal materials used for white light generation, exploration of new host matrices for RE activators is continued. White light generation by vitreous materials was reported for the first time in $1991^{[2]}$. It was obtained from the simultaneous emission of blue, green, and red emitting centers under a unique UV excitation. These materials are borate-based glasses with alkali and alkali-earth as modifiers and contain $\mathrm{Ce}^{3+}$, $\mathrm{Tb}^{3+}$, and $\mathrm{Mn}^{2+}$ as activators. $\mathrm{Ce}^{3+}$ exhibits a broad band emission centered at the border between the UV and visible ranges. In codoped glasses, this ion acts also as a sensitizer transferring a part of its energy to $\mathrm{Tb}^{3+}$ and $\mathrm{Mn}^{2+}$. From that time many researches have focused their attention on the glasses ${ }^{[3-8]}$ as promising matrices for activator ions incorporation. Indeed glasses can be easily and economically fabricated, molded into any shape as well as reveal efficient luminescence. Taking these merits into account, luminescence glasses are potential candidates for developing WLED devices. Research on the possible applications of rare earth (RE) ion doped glasses in fabricating of WLEDs has been conducted by numerous scholars. Guo et al. ${ }^{[4]}$ studied tunable white lumines- cence and energy transfer in $\left(\mathrm{Cu}^{+}\right)_{2}, \mathrm{Eu}^{3+}$ codoped sodium silicate glasses. Rocha et al. investigated the tunable color temperature of $\mathrm{Ce}^{3+} / \mathrm{Eu}^{2+, 3+}$ co-doped low silica aluminosilicate glasses for white lighting ${ }^{[4]}$. Babu et al. achieved white light generation in $\mathrm{Dy}^{3+}$-doped oxyfluoride glass and, transparent glass-ceramics that contain $\mathrm{CaF}_{2}$ nanocrystals ${ }^{[9]}$. Coexistence of two europium states $\left(\mathrm{Eu}^{2+3+}\right)$ in low silica calcium aluminosilicate glasses provides a broad combined tunable orange-red emission $^{[10]}$. At the same time only few papers are devoted to the irradiation effect on tunable white light emission in glasses applied for WLED, in particular in $\gamma$-irradiated $\mathrm{Ag} / \mathrm{Eu}$ co-doped phosphate glass as is discussed in Ref. [11].

Thus the aim of this work was to study the emission properties of pristine and $\beta$-irradiated aluminoborosicate glass doped with $\mathrm{Ce}$ ions in dependence on excitation wavelength, $\mathrm{Ce}$ concentration and registration conditions.

\section{Experimental}

\subsection{Synthesis}

The nominal general composition of the ABS glass was (in mol.\%): 59.77\% $\mathrm{SiO}_{2}, 4.00 \% \mathrm{Al}_{2} \mathrm{O}_{3}, 22.41 \% \mathrm{~B}_{2} \mathrm{O}_{3}$, $12.12 \% \mathrm{Na}_{2} \mathrm{O}, 1.70 \% \mathrm{ZrO}_{2}$. Ce-doped ABS glasses were prepared by adding to the base glass different amounts of cerium oxide $\mathrm{CeO}_{2}$ (from $0.2 \mathrm{~mol} . \%$ to $2 \mathrm{~mol} . \%$ ). The dried mixed powders were first heated at $750{ }^{\circ} \mathrm{C}$ in a $\mathrm{Pt}$

\footnotetext{
* Corresponding author: E. Malchukova (E-mail: evguenia.malchukova@polytechnique.edu)

DOI: $10.1016 / \mathrm{S} 1002-0721(14) 60055-7$
} 
crucible during $10 \mathrm{~h}$, then, it was melted at $1500{ }^{\circ} \mathrm{C}$ for 1 $\mathrm{h}$ and quenched in air. The different glasses were annealed at $500{ }^{\circ} \mathrm{C}$ during a few hours to release strains. Each glass was analyzed by X-ray diffraction, which confirms the amorphous character of glass.

\subsection{Characterization}

All glasses were $\beta$-irradiated with $2.5 \mathrm{MeV}$ electrons (10 $\mathrm{mA}$ ) provided by a Van de Graaff accelerator (LSI, Palaiseau, France) at different integrated doses from $1 \times$ $10^{6}$ to $2 \times 10^{9} \mathrm{~Gy}$.

The luminescence and excitation spectra were measured using a Hitachi F-4500 fluorescence spectrophotometer with the source of Xe lamp (wavelength from 200 to $900 \mathrm{~nm}$ ). The luminescence measurements were performed under different wavelength excitations.

INDI Nd:yttrium aluminum garnet pulsed laser Spectra Physics was used for the luminescence excitation. The collected light was analyzed by a SHAMROCK spectrograph $(F=303 \mathrm{~mm} ; 150$ lines $/ \mathrm{mm}$ grating and a $400 \mu \mathrm{m}$ slit) combined with an ANDOR Istar intensified charge-coupled device. Time delay $(d)$ and gate width $(G)$ were varied from $d=100 \mathrm{~ns}$ and $G=50 \mathrm{~ns}$ to $d=450 \mathrm{~ns}$ and $G=150 \mathrm{~ns}$, respectively. All measurements were done at room temperature.

\section{Results and discussion}

The excitation and emission spectra for the $0.2 \mathrm{~mol} \%$ $\mathrm{CeO}_{2}$-doped aluminoborosilicate glass are presented in Fig. 1. The excitation spectra were obtained by monitoring the emission at 370 and $480 \mathrm{~nm}$, respectively. Two main excitation bands centered at 313 and $340 \mathrm{~nm}$ (UV) region are observed, which are responsible for two very broad emission bands centered at 370 (violet) with FWHM 89 and $420 \mathrm{~nm}$ (violet-blue) with FWHM $100 \mathrm{~nm}$. The violet-blue emission observed under UV excitation is commonly found in many $\mathrm{Ce}^{3+}$-doped materials reported in the literature. The origin of these two emission bands is related to two main sites of the $\mathrm{Ce}^{3+}$ ion in the

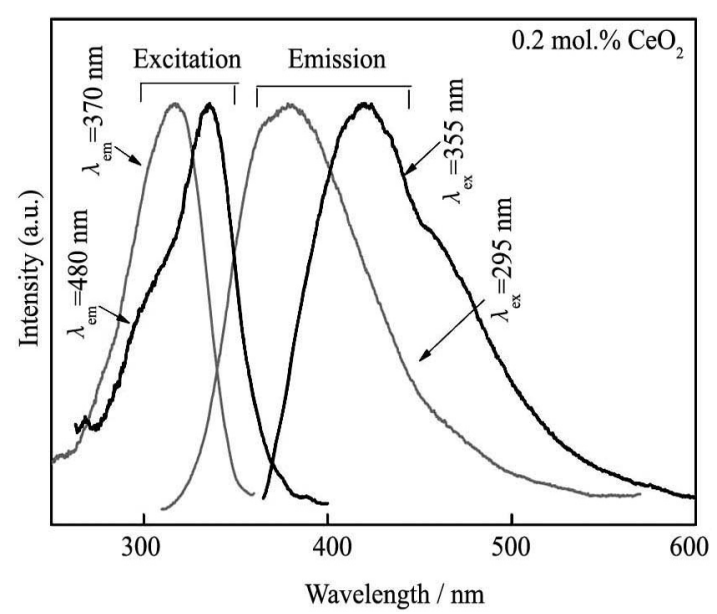

Fig. 1 Excitation and emission spectra of aluminoborosilicate glass doped with $0.2 \mathrm{~mol} \%$ of $\mathrm{CeO}_{2}$ in dependence on excitation wavelength

glass, which will be discussed later.

Thus it can be concluded that with the change of the excitation wavelength the maximum of $\mathrm{Ce}^{3+}$ emission band is shifted to low energies and simultaneously broadened. Moreover, observed "red" shift is also revealed under cerium content increase (Fig. 2), which allows supposing the existence in the aluminoborosilicate glass structure more than one $\mathrm{Ce}^{3+}$-site-high energy (Ce1) and low energy (Ce2). High-energy excitation with 266 or $295 \mathrm{~nm}$ (Fig. 2(a)) leads to the appearance of the luminescence with a maximum at $370 \mathrm{~nm}$, observed only in samples with a low concentration of $\mathrm{CeO}_{2}$ (up to 0.4 mol.\%). In glasses with a high content of $\mathrm{CeO}_{2}(2 \mathrm{~mol} . \%)$ the only Ce2-centers emission is observed at $\lambda_{\mathrm{ex}}=355 \mathrm{~nm}$ attributed to the rapid energy transfer from $\mathrm{Ce} 1$ center to $\mathrm{Ce} 2$ one (Fig. 2(b)). As the cerium concentration increases, the emission intensity of $\mathrm{Ce} 1$ centre is rapidly diminished while intensity of $\mathrm{Ce} 2$ centre decreases rather slowly. The concentration variation of the emission efficiency can be explained by the combination of two factors: a high probability of the energy transfer from $\mathrm{Ce} 1$ to $\mathrm{Ce} 2$ and migration of this energy among the Cel centers subnetwork, which leads to Cel concentration quenching.
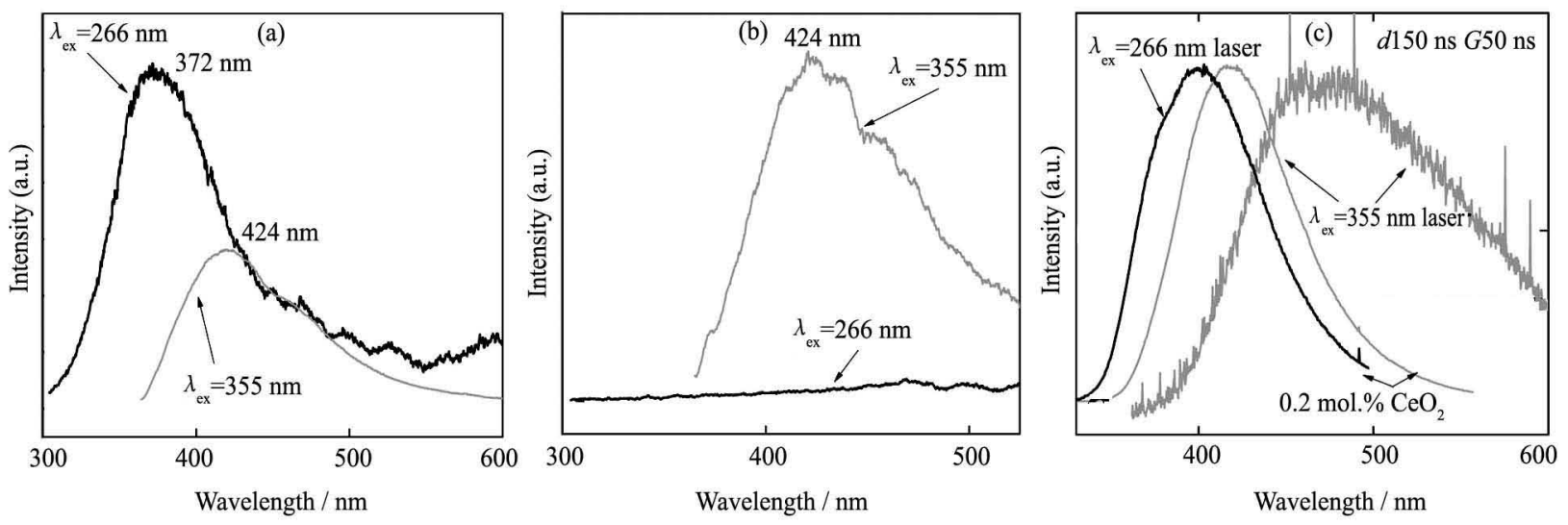

Fig. 2 Evolution of emission spectra of Ce-doped aluminoborosilicate glass with $\mathrm{CeO}_{2}$ concentration and wavelength of excitation (a) $0.2 \mathrm{~mol} . \% \mathrm{CeO}_{2}$; (b) $2 \mathrm{~mol} . \% \mathrm{CeO}_{2}$; (c) $2 \mathrm{~mol} . \% \mathrm{CeO}_{2}$ 
The second assumption seems to be more logical since no increasing of the $\mathrm{Ce} 2$ emission intensity in highlydoped aluminoborosilicate glass was observed. Taking into account the obtained results the different local environments of $\mathrm{Ce}^{3+}$ ion in the aluminoborosilicate glass can be confirmed. In fact this conclusion does not look unexpected because of the atomic structure of glasses namely, lack periodicity and long range order, so the various Ce-centers are non-equivalent and their coordination numbers with the surrounding ligands differ from one site to another one ${ }^{[12]}$.

The emission spectra of $\mathrm{Ce}^{3+}$-doped aluminoborosilicate glass were also obtained using Nd:YAG laser (excitation wavelength 266 and $355 \mathrm{~nm}$ ). The same evolution with $\mathrm{Ce}$ concentration and excitation wavelength as under lamp excitation was found in this case (Fig. 2(c)). Moreover, one can see that the intensity, position and shape of the emission band are strongly affected by the measurement conditions (Fig. 3) which manifests that different $\mathrm{Ce}^{3+}$ centers excitation are observed under definite way of temporal experiment conditions (short-lived or long-lived one). As is shown in Fig. 3, variation of the laser signal delay at a constant slit width for detection of radiation (Gate width) $50 \mu$ s leads to a "red" shift of the maximum of the luminescence band, identified with the presence of one $(\mathrm{Ce} 1)$ or another $(\mathrm{Ce} 2)$ or both $\mathrm{Ce}^{3+}$ centers (Fig. 3). Moreover exposure to ionizing radiation also leads to the formation of $\mathrm{Ce}^{3+}$ ions as can be observed by luminescence measurements. It was found that emission bands are shifted to the low-energy region of the spectrum (both for short- and long-lived centers) (Fig. 4). However this tendency is observed only for the small concentration of cerium oxide $(0.2 \mathrm{~mol} . \%)$. For the highest concentration the maximum of $\mathrm{Ce}^{3+}$ emission in the glass synthesized and $\beta$ irradiated has the same position both for short and long-lived centers, though shifted with respect to the lowest concentration of cerium (from 430 to $450 \mathrm{~nm}$, respectively). The following hypothesis can be taken into consideration: (i) new $\mathrm{Ce}^{3+}$ centers created

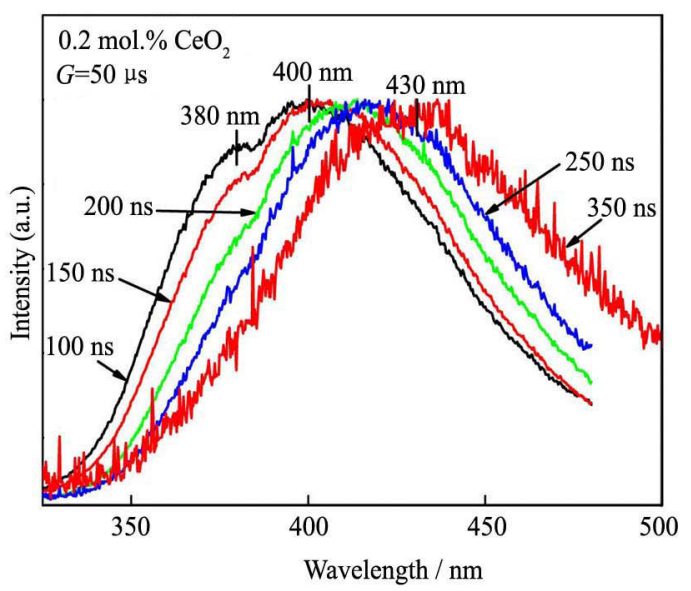

Fig. 3 Emission spectra of aluminoborosilicate glass doped with $0.2 \mathrm{~mol} . \%$ of $\mathrm{CeO}_{2}$ in dependence on registration conditions $\left(\lambda_{\mathrm{ex}}=266 \mathrm{~nm}\right.$ of $\mathrm{Nd}: Y A G$ laser $)$

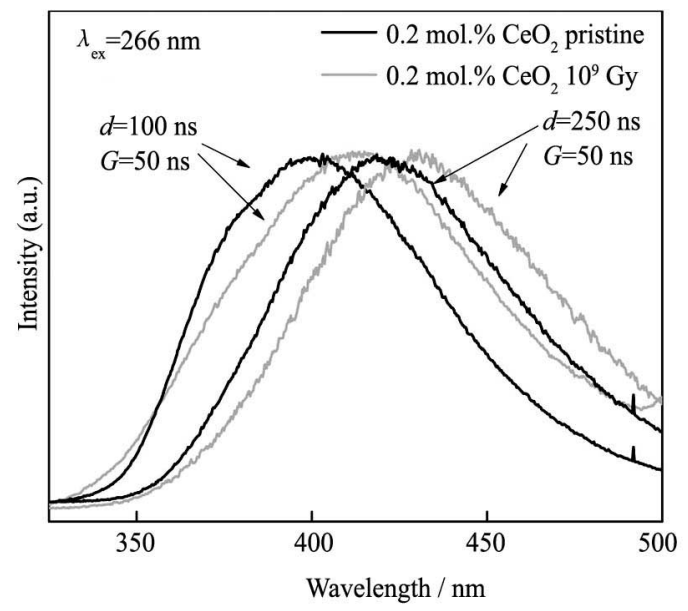

Fig. 4 Emission spectra of pristine and $\beta$-irradiated Ce-doped aluminoborosilicate glass in dependence on $\mathrm{CeO}_{2}$ concentration and registration conditions $\left(\lambda_{\mathrm{ex}}=266 \mathrm{~nm}\right.$ of Nd:YAG laser)

under irradiation, (ii) redistribution of the contributions of the $\mathrm{Ce}^{3+}$ emitting centers to the whole intensity. One can assume appearance of new cerium centers created under irradiation in glass studied. However the position coincidence of the emission maxima for pristine and irradiated glasses doped with $2 \mathrm{~mol} . \%$ of $\mathrm{CeO}_{2}$ contradicts this assumption (Fig. 4(b)). We suppose that the shift is the consequence of contribution to the cerium emission of different $\mathrm{Ce}^{3+}$ emitting centers already presented in the glass host. At the same time intensity redistribution manifests the increase the number of one type of $\mathrm{Ce}^{3+}$ (long-wavelength) in comparison with other one (shortwavelength). It could be assigned to the changes in crystalline field strength and/or covalency of local environment of $\mathrm{Ce}^{3+}$ ions under irradiation, at least for the small concentrations of $\mathrm{CeO}_{2}$ (Fig. 4(a)).

According to the results presented there are two charge states of $\mathrm{Ce}$ ion in the studied glass forming under glass synthesis in the air at high temperature, confirming the $\mathrm{Ce}^{4+}$ reduction process.

In order to speculate with spectral changes discussed above the determination of the relative amounts of $\mathrm{Ce}^{3+}$ and $\mathrm{Ce}^{4+}$ i.e., $\left[\mathrm{Ce}^{4+}\right] /\left[\mathrm{Ce}_{\text {tot }}\right]$ or $\left[\mathrm{Ce}^{3+}\right] /\left[\mathrm{Ce}^{4+}\right]$ is needed since the formation of $\mathrm{Ce}^{3+}$ ions in both cases (for pristine and irradiated glasses) suggests occurrence of the reduction process:

$\mathrm{Ce}^{4+}+\mathrm{e} \rightarrow \mathrm{Ce}^{3+}$

Some data indicate that there are three different $\mathrm{Ce}$ chemical and structural environments in the borosilicate glass ${ }^{[13]}$ : the first two include $\mathrm{Ce}^{3+}$ glass and $\mathrm{Ce}^{4+}$ glass covering $\mathrm{Ce}^{3+} \mu^{4+}$ spices that can be homogeneously distributed in glass network, as well as spices, associated with nonhomogeneous molecular irregularities. The third type corresponds to separate solid solution $\mathrm{Ce}^{4+} \mathrm{CeO}_{2}$ and may also include a nanosized phase. Taking into account these facts and based only on the results of luminescence 
analysis, it is not possible neither to determine the ratio between isolated $\mathrm{Ce}^{3+}$ and $\mathrm{Ce}^{4+}$ ions nor to confirm (or refute) the existence of cerium clusters, since observed $\mathrm{Ce}^{3+}$ emission intensity decrease may be due to both decrease of proportion of $\mathrm{Ce}^{3+}$ ions with increasing $\mathrm{CeO}_{2}$ concentration (as well as the presence of nonradiative energy transfer between two $\mathrm{Ce}^{3+}$ ions) and with the formation of $\mathrm{Ce}^{4+}$ in the crystalline $\mathrm{CeO}_{2}$. It is possible only to consider the presence of a few positions (and environments) for isolated $\mathrm{Ce}^{3+}$ ions.

Considering the presence of different isolated $\mathrm{Ce}^{3+}$ centers in non-irradiated (pristine) aluminoborosilicate glass we can make the following conclusion. Effect of $\beta$-irradiation does not result in the creation of new emission centers but in the emission intensity redistribution between existing $\mathrm{Ce}$ centers at least for concentration less than 2 mol.\% similar to the result reported earlier for Eu-doped aluminoborosilicate glass ${ }^{[14]}$.

\section{Conclusions}

The aluminoborosilicate glasses doped with different concentrations of Ce ions prepared via the melt-quenching technique were exposed to $\beta$-irradiation. Their photoluminescence properties were discussed in detail. Emission varying from violet to blue/green could be generated by tuning the $\mathrm{CeO}_{2}$ concentration, the excitation wavelength and the conditions for emission detection. Ce emission shift caused by the $\beta$-irradiation was also observed. The reason for these phenomena was explained by the ability of the matrix studied to accommodate different sites for $\mathrm{Ce}^{3+}$ ions.

Preliminary studies showed that this glass might have potential applications as a blue-emitting phosphor for near-UV converting white light-emitting diodes.

Acknowledgements: We are grateful to Thierry Pouthier and Vincent Metayer for their contribution during external $\beta$ irradiation experiments.

\section{References:}

[1] Nakamura S. Blue-green light-emitting diodes and violet laser diodes. MRS Bull., 1997, 22: 29.

[2] Zhang J C, Parent C, Flem G Le, Hagenmuller P. White light emitting glasses. J. Solid State Chem., 1991, 93: 17.

[3] Rocha A C P, Andrade L H C, Lima S M, Farias A M,
Bento A C, Baesso M L, Guyot Y, Boulon G. Tunable color temperature of $\mathrm{Ce}^{3+} / \mathrm{Eu}^{2+, 3+}$ co-doped low silica aluminosilicate glasses for white lighting. Opt. Express, 2012, 20(9): 10034.

[4] Guo H, Wei G R, Liu X. Tunable white luminescence and energy transfer in $\left(\mathrm{Cu}^{+}\right)_{2}, \mathrm{Eu}^{3+}$ codoped sodium silicate glasses. Opt. Lett., 2012, 37(10): 1670.

[5] Zhou F, Jiang N, Zhu B, Yang H C, Ye S, Lakshminarayana G, Hao J H, Qiu J R. Multifunctional Bismuth-doped nanoporous silica glass: from blue-green, orange, red, and white light sources to ultra-broadband infrared amplifiers. Adv. Funct. Mater., 2008, 18(9): 1407.

[6] Gouveia-Neto A S, Bueno L A, do Nascimento R F, da Silva E A, da Costa E B, do Nascimento V B. White light generation by frequency upconversion in $\mathrm{Tm}^{3+} / \mathrm{Ho}^{3+} / \mathrm{Yb}^{3+}$ codoped fluorolead germanate glass. Appl. Phys. Lett., 2007, 91(9): 091114

[7] Liu Z J, Chen Q Q, Dai N L, Yu Y, Yang L Y, Li J Y. Tunable white light emitting glass suitable for long-wavelength ultraviolet excitation. J. Non-Cryst. Solids, 2012, 358(23): 3289.

[8] Yu Y, Liu Z J, Dai N L, Sheng Y B, Luan H X, Peng J G, Jiang Z W, Li H Q, Li J Y, Yang L Y. Ce-Tb-Mn co-doped white light emitting glasses suitable for long-wavelength UV excitation. Opt. Express, 2011, 19(20): 19473.

[9] Babu P, Jang K H, Rao C S, Shi L A, Jayasankar C K, Lavin $\mathrm{V}$, Seo H J. White light generation in $\mathrm{Dy}^{3+}$-doped oxyfluoride glass and transparent glass-ceramics containing $\mathrm{CaF}_{2}$ nanocrystals. Opt. Express, 2011, 19(3): 1836.

[10] Lima S M, da Cunha Andrade L H, Silva J R, Bento A C, Baesso M L, Sampaio J A, de Oliveira Nunes L A, Guyot Y, Boulon G. Broad combined orange-red emissions from $\mathrm{Eu}^{2+}$ - and $\mathrm{Eu}^{3+}$-doped low-silica calcium aluminosilicate glass. Opt. Express, 2012, 20(12): 12658.

[11] Fan S J, Yu C L, He D B, Wang X, Hu L L. Tunable white light emission from $\gamma$-irradiated $\mathrm{Ag} / \mathrm{Eu}$ co-doped phosphate glass phosphor. Opt. Mat. Express, 2012, 2(6): 765.

[12] Reisfeld R, Minti H, Patra A, Ganguli D, Gaft M. Spectroscopic properties of cerium in glasses and their comparison with crystals Spectrochimica. Spectrochimica Acta Part A, 1998, 54: 2143.

[13] Darab J G, Li H, Vienna J D. X-ray absorption spectroscopic investigation of the environment of cerium in glasses based on complex cerium alkali borosilicate compositions. J. Non-Cryst. Solids, 1998, 226: 162.

[14] Malchukova E, Boizot B. Divalent europium in b-irradiated aluminoborosilicate glass. J. Am. Ceram Soc., 2010, 93(12): 4005. 